\title{
e-HEALTH - MAKING HEALTHCARE BETTER FOR EUROPEAN CITIZENS: CHALLENGES AND EXPECTATIONS
}

\author{
Diane Whitehouse \\ European Commission, DG Information Society ${ }^{1}$
}

\begin{abstract}
This paper discusses e-Health and focuses on its progress in Europe. In this context, e-Health involves using information, communication and intelligent computing technologies throughout health care systems. It reports that health care systems are successfully using information, communication and intelligent computing technologies, and lists healthcare challenges that lie ahead for further progress.
\end{abstract}

Keywords; e-Health, healthcare, citizen, information, intelligent, communication, technologies

\section{INTRODUCTION}

e-Health matters. It can improve access to healthcare and boost the quality and effectiveness of the services offered. e-Health involves using information and communication technologies throughout health care systems. It offers benefits for both health authorities and professionals, while allowing much more personalised healthcare for patients and citizens. When combined with organisational changes and the development of new skills, eHealth can help to deliver better care for less money within citizen-centred health delivery systems. e-Health is today's tool for substantial productivity gains, while providing tomorrow's instrument for restructured, citizen-

\footnotetext{
${ }^{1}$ The views presented are those of the author and do not necessarily represent the official view of the European Commission on the subject.
} 
centred health care systems and, at the same time, respecting the diversity of Europe's multi-cultural, multi-lingual health care traditions.

\section{2. e-HEALTH PROGRESS}

There are many examples of successful e-Health developments that fall within the ambit of building an Information Society characterised by ambient and intelligent technologies. These include health information networks, electronic health records, telemedicine services, wearable and portable monitoring systems, and health portals. Today, at least four out of five European doctors have an Internet connection, and a quarter of Europeans use the Internet for health information.

Many European research results have now been tested and put into practice. Europe is now in a leading position in the use of electronic health records in primary care and deployment of health (smart) cards. These developments have contributed to the emergence of a new "e-Health industry".

European Member States want to take an e-Health agenda forward. An emerging framework for concerted actions and synergies in e-Health based on an open method of coordination is envisaged that provides a favourable environment for the integration of related policies at a Community level. eHealth plays a clear role in the European Union's $e$ Europe strategy of stronger growth - the vision set out by the Lisbon European Council in March $2000^{2}$. To move ahead, action will be required within several important policy areas that range from research and the roll-out of broadband networks in telecommunications, to action in public health.

\section{CHALLENGES}

Healthcare systems around the globe are currently facing major challenges ${ }^{4}$. For the European Union, these include:

- rising demand for health and social services, due to an ageing population and higher income and educational levels;

- the increasing expectations of citizens who want the best care available, and at the same time to experience a reduction in inequalities in access to good health care;

\footnotetext{
${ }^{2}$ European Council (2000), Presidency Conclusions. Lisbon European Council. 23-24 March, 2000.

${ }^{3}$ COM(2002) 263 final. eEurope 2005: An information society for all: An action plan to be presented in view of the Sevilla European Council, 21/22 June, 2002. Brussels, 28.5.2000.

${ }^{4}$ COM (2001) 723 final The future of health care and care for the elderly: guaranteeing accessibility, quality and financial viability.
} 
- increasing mobility of patients ${ }^{5}$ and health professionals including the opening of the internal markets in services - that may result in a higher demand for reimbursable cross-border healthcare products and services;

- the need to reduce the so-called 'disease burden", ${ }^{, 7}$ and to respond to emerging disease risks;

- the difficulties experienced by public authorities in matching investment in technology with investment in the complex organisational changes needed to exploit its potential;

- the need to limit occupational accidents and diseases, to reinforce well-being at work and to address new forms of work-related diseases ${ }^{8}$;

- management of huge amounts of health information that need to be available securely, accessibly, and in a timely manner at the point of need, processed efficiently for administrative purposes; and, lastly,

- the need to provide the best possible health care under limited budgetary conditions.

\footnotetext{
${ }^{5}$ High level reflection process on patient mobility and healthcare developments in the EU, 2003.

${ }^{6}$ Regulation 1408/71 that co-ordinates social security legal schemes has recently been amended to streamline and modernise access to health care across borders, particularly when undue delays occur in the patient's home Member State. In January 2004, the Commission tabled a proposal for a directive on freedom of provision of services which lays down a framework for the provision of health care services in the internal market and for their reimbursement by the relevant health insurance institutions.

${ }^{7}$ The disease burden is a measure of the health of a population and quantifies the total impact of disease in terms of incidence of mortality, disability, and the cost of illness.

${ }^{8}$ The costs of accidents at work and occupational diseases are between $2.6 \%$ and $3.8 \%$ of national gross domestic product in the various European Member States. For further details, see Communication from the Commission on the practical implementation of the provisions of the Health and Safety at Work Directives. COM(2004) 62 final, February 2004.
} 